\title{
Twin Studies of Atopic Dermatitis: Interpretations and Applications in the Filaggrin Era
}

\author{
Camilla Elmose $^{1}$ and Simon Francis Thomsen ${ }^{1,2}$ \\ ${ }^{1}$ Department of Dermatology, Bispebjerg Hospital, 2400 Copenhagen NV, Denmark \\ ${ }^{2}$ Center for Medical Research Methodology, Department of Biomedical Sciences, University of Copenhagen, \\ 2200 Copenhagen N, Denmark \\ Correspondence should be addressed to Simon Francis Thomsen; simonfrancisthomsen@gmail.com
}

Received 3 August 2015; Accepted 2 September 2015

Academic Editor: Stephen P. Peters

Copyright (c) 2015 C. Elmose and S. F. Thomsen. This is an open access article distributed under the Creative Commons Attribution License, which permits unrestricted use, distribution, and reproduction in any medium, provided the original work is properly cited.

\begin{abstract}
Aim. The aim of this study was to conduct a systematic review of population-based twin studies of (a) the concordance and heritability of $\mathrm{AD}$ and (b) the relationship between $\mathrm{AD}$ and asthma and, furthermore, to reinterpret findings from previous twin studies in the light of the emerging knowledge about filaggrin and its role in the atopic march and provide suggestions for future research in this area. Methods. We identified all twin studies (published after 1970) that have calculated the concordance rate and/or the heritability of $\mathrm{AD}$, or the genetic and environmental correlations between $\mathrm{AD}$ and asthma. Results. Reported concordance rates for $\mathrm{AD}$ ranged, respectively. From 0.15 to 0.86 for $\mathrm{MZ}$ and from 0.05 to 0.41 for $\mathrm{DZ}$ twins, with an overall ratio of MZ: DZ twins of approximately three. The heritability of $\mathrm{AD}$ was estimated to be approximately $75 \%$, and the association between $\mathrm{AD}$ and asthma was around $85 \%$ explained by genetic pleiotropy. Conclusions. Genetic factors account for most of the variability in $\mathrm{AD}$ susceptibility and for the association between AD and asthma. Controversy remains as to whether the atopic diseases are causally related or whether they are diverse clinical manifestations of a common, underlying (genetic) disease trait. Future twin studies may help solve this enigma.
\end{abstract}

\section{Introduction}

Atopic dermatitis $(\mathrm{AD})$ is a common, inflammatory skin disease that primarily affects small children. $50 \%$ of cases appear within the first year of life, while $95 \%$ of cases have an onset before the age of five [1]. AD is a heterogeneous disease [2]; moderate and severe cases are usually easy to recognize, although differential diagnoses such as Netherton syndrome and cutaneous lymphoma should be considered, unlike mild and intermittent cases, which are less easily identifiable. During the last decades, the prevalence of $\mathrm{AD}$ has increased markedly, and in many Western countries, as much as onefifth of all individuals are affected during their lifetime [3]. It is generally accepted that the rise in prevalence of $\mathrm{AD}$, at least in part, can be explained by widespread environmental hygienic changes occurring in the last part of the 20th century. These changes are thought to have led to pronounced changes in the human microflora impacting pre- and perinatally on the risk of $\mathrm{AD}$ and other atopic diseases via complex interactions with the host immune system [4].
Pathophysiologically, two (complementary) hypotheses are commonly evoked to explain the inflammatory lesions of $\mathrm{AD}$. The first is the immunological hypothesis, which argues that $\mathrm{AD}$ results from an imbalance of $\mathrm{T}$ cells [5]. In the acute phase of $\mathrm{AD}$, the Th2 cytokines IL-3, IL-4, IL-5, and IL-13 dominate leading to increased levels of IgE, whereas the Th1 differentiation is correspondingly inhibited. In chronic $\mathrm{AD}$, however, IFN- $\gamma$, IL-17, and IL-22 are important [3], suggesting that both Th1 and Th2 cells are contributors to the pathogenesis of $\mathrm{AD}$. The second hypothesis is the so-called leaky skin barrier hypothesis, which is based on the observation that individuals with mutations in the filaggrin gene $(F L G)$, which encodes the epidermal structural protein filaggrin, are at increased risk of developing AD [6]. Notably, individuals with FLG mutations experience a disrupted skin barrier, phenotypically characterized by dry, fissured skin, facilitating penetration of allergens, immunological dysfunction, and consequently an increased risk of developing eczema. Up to $50 \%$ of all patients with AD carry FLG mutations, making it the strongest known risk factor for $\mathrm{AD}[6]$. 
Importantly, individuals with $\mathrm{AD}$ have an increased risk of developing hay fever and asthma $[13,17]$. The basis of this association is imperfectly understood, and controversy remains as to whether the atopic diseases are causally related or whether they are diverse clinical manifestations of a common underlying (genetic) disease trait. The leading theory, however, follows from the leaky skin barrier hypothesis: among individuals with epidermal barrier defects, the skin acts as the site of primary sensitization with secondary reactivity in the airways [18].

Twin studies have been used to examine the relative importance of genetic and environmental factors for $\mathrm{AD}$ and also for the relationship between $\mathrm{AD}$ and related atopic diseases. Particularly, the concordance rate of AD is consistently higher for monozygotic (MZ) than for dizygotic (DZ) twins [13], indicating that genetic factors play a major role in the development of AD. Furthermore, twin studies have shown that genetic factors explain a sizable proportion of the cooccurrence of $\mathrm{AD}$ and the other atopic diseases, primarily asthma [15]. However, several of these studies were conducted before the discovery of filaggrin and its role in the atopic march, and consequently, this important information has been lacking in the interpretation of these findings.

Twin studies are a well-known and efficient method of estimating the relative genetic and environmental contribution to various diseases. Twin studies assume that, in principle, MZ twins are perfectly genetically matched, while DZ twins, like ordinary siblings, share half their segregating genes. Furthermore, $M Z$ twins are assumed to share environmental risk factors to the same extent as DZ twins, and therefore, by comparing $\mathrm{MZ}$ with $\mathrm{DZ}$ twins, it is possible to estimate the relative impact of genetic and environmental factors on a given disease. Furthermore, twin studies allow estimation of the degree of overlap between genetic and environmental factors for related diseases.

Herein, we present a systematic review of (a) populationbased twin studies of the concordance and heritability of AD and (b) twin studies of the relationship between AD and asthma. Furthermore, we reinterpret the findings from these previous twin studies in the light of the emerging knowledge about filaggrin and its role in the atopic march and provide suggestions for future studies in this area.

\section{Methods}

We performed searches in PubMed, Google Scholar, Scopus, and Embase combining the words "atopy," "atopic dermatitis," and "eczema," with "heritability," "concordance," "correlation," "twin," and "twin study." In a second search we combined the words "asthma" and "twin"/"twin study" with the words "eczema" and "atopic dermatitis." We identified recent twin studies (published after 1970) that have calculated either the concordance rate for $\mathrm{AD}$ or the genetic and environmental correlations between $\mathrm{AD}$ and asthma. A total of 8 publications addressing the first question and a further 3 publications addressing the second question were identified. Each publication's reference list was scrutinized for missed cross-references.
2.1. Genetic Influence on Atopic Dermatitis. Several twin studies have estimated concordance rates for AD. Most of these have been based on questionnaire data, gathered through either parent-report, self-report, or both, depending on the age of the participants (Table 1).

In 1971, Edfors-Lubs [7] conducted a large populationbased study comprising 7000 twin pairs, aged 42-81 years, who were recruited through the Swedish Twin Registry. The study found concordance rates of 0.154 and 0.045 for MZ and DZ twins, respectively, indicating a significant influence of genetic factors on $\mathrm{AD}$.

In a population-based study from 1986, Schultz Larsen et al. [8] examined a group of 592 like-sexed Danish twin pairs at school age, using questionnaire and clinical data. Participants were enrolled through the Danish Civil Registration System and were selected on the basis of affirmative responses to questions concerning $\mathrm{AD}$ as well as on the basis of clinical signs of $\mathrm{AD}$. The probandwise concordance rates were 0.86 and 0.21, respectively, in MZ and DZ twins. In 1993, the same authors extended their findings by conducting a similar study [9] of 812 twin pairs, aged 8-22 years, using the same methodology: concordance rates were 0.72 and 0.23 , in $\mathrm{MZ}$ and DZ twins.

In another population-based study of Swedish children (1480 twin pairs), 7-9 years of age, from 1997, Lichtenstein and Svartengren [10] found correlations in the liability to $\mathrm{AD}$ of 0.54 (MZ twins) and 0.35 (DZ twins) in boys, and 0.73 and 0.40 in girls, respectively, demonstrating a difference between sexes with a larger ratio of $\mathrm{MZ}$ to $\mathrm{DZ}$ concordance rates of eczema in girls. The study concluded, based on these differences in concordance rates, that, in boys, $75 \%$ of the individual susceptibility to $\mathrm{AD}$ was ascribable to additive genetic differences, whereas the remaining 25\% was due to nonshared environmental factors. However, in girls, there was also an indication of an effect of shared environment ( $16 \%$ of the variation), which was, however, not statistically significant.

In a study from 2001, Strachan et al. [11] studied 873 female twin pairs, aged 18-72 years recruited through the St. Thomas UK Adult Twin Registry. The study found concordance rates of 0.51 and 0.47 in $\mathrm{MZ}$ twins below and above 50 years of age, respectively. For DZ twins, the same rates were 0.34 and 0.09 . The St. Thomas Twin Registry comprises mainly female twins recruited through media campaigns.

In 2005 Nystad et al. [12] examined Norwegian twins in a population-based study of 3334 pairs recruited from The Medical Birth Registry using the International Studies of Asthma and Allergies in Childhood (ISAAC) questionnaires [3]. In MZ twin pairs, concordance rates of 0.43 and 0.44 were found in boys and girls, respectively, whereas for DZ twin pairs the corresponding rates were 0.06 and 0.10 , thus demonstrating a greater $\mathrm{MZ} / \mathrm{DZ}$ ratio in boys than in girls.

In 2007, Thomsen et al. [13] conducted a study of 11515 Danish Twin pairs, 12-41 years of age. Subjects were enrolled through the Danish Twin Registry. The study reported concordance rates of self-reported $\mathrm{AD}$ of 0.57 in $\mathrm{MZ}$ twins and 0.21 in $\mathrm{DZ}$ twins corresponding to a heritability of $\mathrm{AD}$ of around $80 \%$. 
TABLE 1: Population-based twin studies of the concordance and heritability of atopic dermatitis.

\begin{tabular}{|c|c|c|c|c|c|c|c|c|}
\hline Study & Country & $\begin{array}{c}\text { Age } \\
\text { (years) }\end{array}$ & $\begin{array}{c}N \\
\text { (pairs) }\end{array}$ & $\mathrm{MZ}$ rate & $\mathrm{DZ}$ rate & $\begin{array}{l}\mathrm{MZ} / \mathrm{DZ} \\
\text { ratio }\end{array}$ & $\begin{array}{l}\text { Heritability } \\
(\%)\end{array}$ & $\begin{array}{l}\text { Diagnostic } \\
\text { method }\end{array}$ \\
\hline Edfors-Lubs (1971) [7] & Sweden & $42-81$ & 6996 & 0.154 & 0.045 & 3.42 & & Self-report \\
\hline $\begin{array}{l}\text { Schultz Larsen et al. (1986) } \\
\text { [8] }\end{array}$ & Denmark & $7-21$ & 592 & 0.86 & 0.21 & 4.1 & & Clinical examination \\
\hline Larsen (1993) [9] & Denmark & $8-22$ & 812 & 0.72 & 0.23 & 3.13 & & Clinical examination \\
\hline $\begin{array}{l}\text { Lichtenstein and } \\
\text { Svartengren (1997) [10] }\end{array}$ & Sweden & $7-9$ & 1339 & & & & & Parent-report \\
\hline Boys & & & & 0.54 & 0.35 & 1.54 & 74 & \\
\hline Girls & & & & 0.73 & 0.40 & 1.83 & 71 & \\
\hline Strachan et al. (2001) [11] & UK & $18-72$ & 873 & & & & & Clinical examination \\
\hline$<50$ & & & & 0.51 & 0.34 & 1.50 & & \\
\hline$>50$ & & & & 0.47 & 0.09 & 5.22 & & \\
\hline Nystad et al. (2005) [12] & Norway & $18-35$ & 3334 & & & & 69 & Self-report \\
\hline Boys & & & & 0.43 & 0.06 & 7.17 & & \\
\hline Girls & & & & 0.44 & 0.10 & 4.40 & & \\
\hline Thomsen et al. (2007) [13] & Denmark & $12-41$ & 11515 & 0.57 & 0.21 & 2.71 & & Self-report \\
\hline Boys & & & & & & & 82 & \\
\hline Girls & & & & & & & 80 & \\
\hline Jäderberg et al. (2012) [14] & Denmark & $3-20$ & 9694 & & & & & $\begin{array}{l}\text { Self-report/parent- } \\
\text { report }\end{array}$ \\
\hline Assisted reproduction & & & & & & & 86 & \\
\hline Spontaneous conception & & & & & & & 78 & \\
\hline
\end{tabular}

MZ, monozygotic; DZ, dizygotic.

TABLE 2: Population-based twin studies of the association between atopic dermatitis and asthma.

\begin{tabular}{|c|c|c|c|c|c|c|}
\hline Study & Country & $\begin{array}{c}\text { Age } \\
\text { (years) }\end{array}$ & $\begin{array}{c}N \\
\text { (pairs) }\end{array}$ & $\begin{array}{l}\text { Phenotypic } \\
\text { correlation }\end{array}$ & $\begin{array}{l}\text { Proportion due to } \\
\text { genetic factors (\%) }\end{array}$ & $\begin{array}{l}\text { Diagnostic } \\
\text { method }\end{array}$ \\
\hline $\begin{array}{l}\text { Lichtenstein and } \\
\text { Svartengren (1997) [10] }\end{array}$ & Sweden & $7-9$ & 1339 & 0.30 & 85 & Parent-report \\
\hline Thomsen et al. (2006) [15] & Denmark & $12-41$ & 11231 & 0.40 & 81 & Self-report \\
\hline $\begin{array}{l}\text { van Beijsterveldt and } \\
\text { Boomsma (2007) [16] }\end{array}$ & Netherlands & 5 & 8633 & 0.55 & 82 & Parent-report \\
\hline
\end{tabular}

Phenotypic correlation is the correlation between the individual liabilities to atopic dermatitis and asthma.

Proportion due to genetic factors is the proportion of phenotypic correlation explained by genetic factors shared between atopic dermatitis and asthma.

Finally, a study by Jäderberg et al. from 2012 [14] examined a group of 9694 Danish twin pairs, 3-20 years of age recruited through the Danish Twin Registry, aiming to determine the impact of assisted reproduction on the risk of atopic diseases. The study found that $\mathrm{AD}$ was equally prevalent in twins born after assisted reproduction and spontaneous conception, respectively, with genetic effects accounting for $91 \%$ and $86 \%$ of $\mathrm{AD}$ in these two groups of twins. The difference in heritability was not statistically significant, demonstrating no mediating effect of assisted reproduction on $\mathrm{AD}$ development.

2.2. Association between Atopic Dermatitis and Asthma. Only a few studies have examined the association between $A D$ and asthma in twins (Table 2). Particularly, in the previously mentioned study of Swedish twin children from 1997, Lichtenstein and Svartengren [10] found a phenotypic correlation between $\mathrm{AD}$ and asthma of 0.30 . As much as $85 \%$ of this correlation in liability between the two diseases was ascribable to genetic factors, while the remaining $15 \%$ was due to nonshared environmental factors.

Also, among Danish adolescent and adult twins, Thomsen et al. [15] found a phenotypic correlation between $\mathrm{AD}$ and asthma of 0.40 and furthermore showed that $81 \%$ of the proportion of phenotypic overlap between $\mathrm{AD}$ and asthma was due to genetic pleiotropy, the remaining 19\% being due to environmental factors. Additionally, atopic diseases were significantly associated within the same individual with an OR of developing asthma if one had eczema of almost five, and also the risk of developing any atopic disease 
was dramatically increased in a subject if the subject's twin brother or sister was affected, either by the same disease or by another. The effect was more pronounced in MZ twins compared with $\mathrm{DZ}$ twins, indicating that asthma and $\mathrm{AD}$ are genetically related [15].

In 2007, van Beijsterveldt and Boomsma [16] reported a correlation between $\mathrm{AD}$ and asthma of 0.55 , and that pleiotropy explained $82 \%$ of this correlation, the remaining $18 \%$ being explained by environmental factors. The study population consisted of 86335 -year-old twin pairs and was recruited through the Netherlands Twin Register, which comprises volunteer members, representing about $50 \%$ of all multiple births in the Netherlands.

2.3. Strengths and Limitations of the Reviewed Studies. Most of the identified studies rely solely on questionnaire responses. Only Schultz-Larsen et al. $[8,9]$ and Strachan et al. [11] have used clinical examination in order to diagnose subjects with eczema. Accordingly, there is a great possibility of recall bias in most of the previous twin studies. In contrast, Strachan et al. [11] argue that the combination of clinical examination, involvement of parents, and strictly defined diagnostic criteria makes it unlikely that recall bias should have affected the results. A particular strength of this UK study is that all clinical examinations were made by the same dermatologist, thus excluding the chance of interobserver bias. An obvious weakness of the same study is that the twin sample does not represent the general population, as the St. Thomas Twin Registry comprises twins mainly recruited through media campaigns. The authors however argue that major volunteer bias is unlikely, since recruitment did not inform participants of the specific hypotheses being tested.

An obvious strength of the Danish, Swedish, and Norwegian studies is that they were performed in countries that enable extraction of representative samples of the general population, as very large and structured twin registries are available in the Nordic countries [19]. In contrast, the Netherlands Twin Register relies on volunteer members and thus only represents around $50 \%$ of multiple births in the Netherlands. Therefore the population in the study by van Beijsterveldt and Boomsma [16] does not represent the general population as well as the ones in the Scandinavian studies.

All of the reviewed publications are based on twin samples, which might intrinsically bias the results, as it cannot be excluded that twins per se constitute a special population. According to van Beijsterveldt and Boomsma [16], several factors cause twins to deviate from the general population. In many instances, twin deliveries occur before 37 weeks of gestation [20], and therefore twins have an increased risk of lung damage, which in turn may increase the risk of developing asthma [21]. Indeed, in the Dutch study there was an indication that the frequency of asthma in the study group exceeded that of the general population [16]. Conversely, there is also evidence that the prevalence rate of asthma may be lower in twins than in singletons, since growing up with a cotwin increases the chance of exposure to infections in early life, which in turn protects against the development of allergic diseases [22].

\section{Discussion}

Since 1970, a total of eight publications have examined the heritability of $\mathrm{AD}$ using twin data. Older studies are considered too small and biased, in part because of lack of registration systems in most countries [7]. For MZ twins, concordance rates range between 0.15 and 0.86 , while for $\mathrm{DZ}$ twins, the corresponding numbers range from 0.05 to 0.41 . However, as the concordance depends on the prevalence of the disease, and since the studies reviewed herein represent a period in which $\mathrm{AD}$ has increased markedly in prevalence, the ratio between $\mathrm{MZ}$ and $\mathrm{DZ}$ concordances seems a more appropriate measure of the genetic influence on $\mathrm{AD}$. Although the reviewed studies vary in terms of age group, period, and country of origin, they all show that MZ twins are more concordant for $\mathrm{AD}$ than are $\mathrm{DZ}$ twins with a ratio between these concordances of around three, demonstrating great importance of genetic factors in the development of AD. The overall heritability of $\mathrm{AD}$ estimated from previous studies is around $75 \%$.

Of note, twin studies of the association between $\mathrm{AD}$ and asthma have concluded that genetic pleiotropy explains as much as $85 \%$ of this association $[10,15,16]$. These findings suggest that $\mathrm{AD}$ and asthma, to a large extent, are genetically related. However, all studies of the association between AD and asthma were conducted before, or very shortly after, the discovery of the role of FLG mutations in the progression of the atopic march. Particularly, in 2006, pioneering work by Palmer et al. [6] revealed that two different loss-of-function variants in FLG, carried by around 9\% of the European population, are strong predisposing factors for AD. Furthermore, it was observed that FLG mutations are also associated with asthma, but only in the context of AD. With this work and later confirmed in several subsequent independent populations [18] an emerging paradigm for understanding the progression of the atopic march was founded. In 2009, a systematic review and meta-analysis by van den Oord and Sheikh showed that, among individuals with FLG mutations, the risk of $\mathrm{AD}$ was increased about two times in family studies and almost five times in case-control studies [23]. Also the risk of asthma was increased, but only in those with coexistent eczema. These findings provide strong supporting evidence that FLG defects constitute an important risk factor both for the development of eczema and for the later progression to other atopic diseases.

The atopic march is the sequential progression of $\mathrm{AD}$ to asthma and allergic rhinitis during the first years of life. According to the leaky skin barrier hypothesis it is assumed that epidermal defects in genetically predisposed individuals result in primary percutaneous sensitization, which later leads to secondary reactivity in the airways following allergen or irritant exposure [18]. Several studies have indicated a close relationship between the atopic diseases on the individual level [17, 24], and a systematic review by Wüthrich [25] showed a lifetime risk of allergic rhinitis and asthma in individuals with $\mathrm{AD}$ of $40-60 \%$. Thus, a close association between atopic diseases has long been known and before the discovery of filaggrin it was reasonable to believe that this association was ascribable to a common genetic background 
for the atopic diseases. However, the discovery that FLG mutations predispose to both $\mathrm{AD}$, and also to asthma in the context of $\mathrm{AD}$, renders it possible that the high degree of genetic overlap between $\mathrm{AD}$ and asthma found in twin studies represents a causal relationship between $\mathrm{AD}$ and asthma mediated through a filaggrin-deficient skin barrier rather than because of true genetic pleiotropy. Still, this association might only exist for certain types of asthma, primarily classical atopic asthma with early onset, whereas adult-onset asthma or nonatopic asthma may result from different pathways.

3.1. Directions for Future Research. The chain of events that links AD to asthma is complex and involves a multitude of hereditary and developmental factors that exert their effect in the context of environmental exposures. Today, in the "postfilaggrin era," we have indications to believe that the demonstrated link between the different atopic diseases is mediated through a congenital skin barrier deficiency caused by mutations in important structural proteins of the skin, particularly filaggrin. The twin studies reviewed herein, and most other previous studies of singleton populations, however, are retrospective, mainly based on questionnaire data. Therefore, in the future, it would be interesting to examine the progression of $\mathrm{AD}$ to asthma and hay fever in prospective twin studies. In such studies, FLG variants as well as clinical data on the onset, severity, morphology, and anatomical distribution of $\mathrm{AD}$ should be included. Also, FLG null alleles are associated primarily with early-onset AD [26] and with persistence of AD from childhood into adulthood [27], but not with late-onset $\mathrm{AD}[28]$ although it is associated with certain anatomical patterns of adult $\mathrm{AD}$, particularly foot and hand eczema [29]. However, whether FLG variants are associated with the progression of asthma to $\mathrm{AD}$ deserves further study.

Given the perception that the link between $\mathrm{AD}$ and asthma is causal it might also be interesting to address the leaky barrier hypothesis further in the context of defects in other structural epidermal and epithelial (airway or gut) proteins, apart from filaggrin. Such studies investigating other factors involved in barrier function might help explain why less than half of all patients with $\mathrm{AD}$ develop asthma and, conversely, why many without $\mathrm{AD}$ and $F L G$ defects still develop asthma. Interestingly, some studies have suggested specific epithelial barrier proteins to have implications for asthma development, even in the absence of AD. For example, Hackett et al. [30] found that, in the airway epithelia of patients with asthma, the membrane expression of caveolin-1 was significantly lower compared to that of subjects without asthma. Importantly, reduced caveolin-1 expression was accompanied by loss of junctional E-cadherin and b-catenin expression, disrupted epithelial barrier function, and increased levels of the proallergic cytokine thymic stromal lymphopoietin. Twin studies might prove valuable in the further substantiation of these findings. An opportunity could be to study twin pairs discordant for barrier protein gene mutations in order to look for differences in atopic disease risk between the twins. Also, $\mathrm{MZ}$ twin pairs concordant for gene mutations associated with epithelial barrier dysfunction would serve as an interesting sample for studying gene-environment interaction in atopic diseases if MZ pairs discordant for environmental exposures can be identified. Moreover, studying twins would enable us to estimate to what extent mutated barrier protein genes account for the variance in $\mathrm{AD}$ and asthma susceptibility, that is, the proportion of heritability explained by FLG and other mutated barrier protein alleles.

If the progression from $\mathrm{AD}$ to asthma, at least in part, is caused by deficient epidermal proteins, another area that might be interesting to address are preventive strategies for these diseases. In 2010, Simpson et al. [31] studied the effect of early skin barrier protection in 22 neonates, all at high risk of developing AD. All subjects were treated with emollient therapy from birth, and the results suggested a protective effect of this treatment, with only $15 \%$ of subjects developing AD in the study group, compared with $30-50 \%$ in previous studies [32]. Recently, similar findings from two randomised controlled studies emphasize the relevance of these measures [33, 34]. Future twin studies might focus on the impact of skin barrier protection in the primary prevention of both $\mathrm{AD}$ and asthma.

Another key area of future research where twin studies are expected to be particularly valuable is epigenetics $[35,36]$. Epigenetics is the study of heritable changes of a disease that are not caused by changes in the DNA sequence. Examples include DNA methylation, posttranscriptional histone modification, and modification of noncoding RNAs. As MZ twins are genetically identical, and also because they share many environmental exposures, it is puzzling that in many instances only one twin develops $\mathrm{AD}$ and asthma while the other remains unaffected or affected to a lesser degree. In epigenetics, proteins that attach to silencer regions of DNA will cause these regions to express differently, thus leading to differences in disease expression between individuals. Accordingly, such epigenetic studies of, for example, MZ twins discordant for $\mathrm{AD}$ and asthma might provide valuable clues in this context, as these mechanisms may partly explain the relatively high degree of discordance between MZ twins for these diseases [36].

Previous twin studies have revealed that both genetic [37] and nongenetic [38] factors determine the diversity of the gut microbiome. Also, twin studies have indicated an impact of a reduced microbial diversity in the development of conditions such as Crohn's disease [39] and Hodgkin lymphoma [40]. In relation to $\mathrm{AD}$ and asthma future twin studies should explore whether or not these findings also pertain to these diseases, and, particularly, whether reduced microbial diversity is a consequence of disease, its treatment, or a particularly hygienic environment. If relevant in this context, it would be interesting to examine the possibilities of using this knowledge in the prevention and treatment of $\mathrm{AD}$ and asthma.

\section{Conclusion}

This systematic review of twin studies showed that genetic factors account for most of the variability in $\mathrm{AD}$ susceptibility and also for the association between $\mathrm{AD}$ and asthma. However, controversy remains as to whether the atopic diseases are causally related or whether they are diverse clinical manifestations of a common, underlying (genetic) disease trait. Future twin studies may help solve this enigma. 


\section{Conflict of Interests}

The authors declare that there is no conflict of interests regarding the publication of this paper.

\section{References}

[1] H. C. William, "Clinical practice. Atopic dermatitis," The New England Journal of Medicine, vol. 352, no. 22, pp. 2314-2324, 2005.

[2] K. Eyerich and N. Novak, "Immunology of atopic eczema: overcoming the Th1/Th2 paradigm," Allergy, vol. 68, no. 8, pp. 974-982, 2013.

[3] M. I. Asher, S. Montefort, B. Björkstén et al., "Worldwide time trends in the prevalence of symptoms of asthma, allergic rhinoconjunctivitis, and eczema in childhood: ISAAC Phases One and Three repeat multicountry cross-sectional surveys," The Lancet, vol. 368, no. 9537, pp. 733-743, 2006.

[4] D. P. Strachan, "Hay fever, hygiene, and household size," British Medical Journal, vol. 299, no. 6710, pp. 1259-1260, 1989.

[5] T. Bieber, "Atopic dermatitis 2.0: from the clinical phenotype to the molecular taxonomy and stratified medicine," Allergy, vol. 67, no. 12, pp. 1475-1482, 2012.

[6] C. N. A. Palmer, A. D. Irvine, A. Terron-Kwiatkowski et al., "Common loss-of-function variants of the epidermal barrier protein filaggrin are a major predisposing factor for atopic dermatitis," Nature Genetics, vol. 38, no. 4, pp. 441-446, 2006.

[7] M. L. Edfors-Lubs, "Allergy in 7000 twin pairs," Acta Allergologica, vol. 26, no. 4, pp. 249-285, 1971.

[8] F. Schultz Larsen, N. V. Holm, and K. Henningsen, "Atopic dermatitis: a genetic-epidemiologic study in a population-based twin sample," Journal of the American Academy of Dermatology, vol. 15, no. 3, pp. 487-494, 1986.

[9] F. S. Larsen, "Atopic dermatitis: a genetic-epidemiologic study in a population-based twin sample," Journal of the American Academy of Dermatology, vol. 28, no. 5, pp. 719-723, 1993.

[10] P. Lichtenstein and M. Svartengren, "Genes, environments, and sex: factors of importance in atopic diseases in 7-9-year-old Swedish twins," Allergy, vol. 52, no. 11, pp. 1079-1086, 1997.

[11] D. P. Strachan, H. J. Wong, and T. D. Spector, "Concordance and interrelationship of atopic diseases and markers of allergic sensitization among adult female twins," Journal of Allergy and Clinical Immunology, vol. 108, no. 6, pp. 901-907, 2001.

[12] W. Nystad, E. Røysamb, P. Magnus, K. Tambs, and J. R. Harris, "A comparison of genetic and environmental variance structures for asthma, hay fever and eczema with symptoms of the same diseases: a study of Norwegian twins," International Journal of Epidemiology, vol. 34, no. 6, pp. 1302-1309, 2005.

[13] S. F. Thomsen, C. S. Ulrik, K. O. Kyvik et al., "Importance of genetic factors in the etiology of atopic dermatitis: a twin study," Allergy and Asthma Proceedings, vol. 28, no. 5, pp. 535-539, 2007.

[14] I. Jäderberg, S. F. Thomsen, K. O. Kyvik, A. Skytthe, and V. Backer, "Atopic diseases in twins born after assisted reproduction," Paediatric and Perinatal Epidemiology, vol. 26, no. 2, pp. 140-145, 2012.

[15] S. F. Thomsen, C. S. Ulrik, K. O. Kyvik, L. R. Skadhauge, I. Steffensen, and V. Backer, "Findings on the atopic triad from a Danish twin registry," The International Journal of Tuberculosis and Lung Disease, vol. 10, no. 11, pp. 1268-1272, 2006.

[16] C. E. M. van Beijsterveldt and D. I. Boomsma, "Genetics of parentally reported asthma, eczema and rhinitis in 5-yr-old twins," European Respiratory Journal, vol. 29, no. 3, pp. 516-521, 2007.

[17] A. E. van der Hulst, H. Klip, and P. L. P. Brand, "Risk of developing asthma in young children with atopic eczema: a systematic review," Journal of Allergy and Clinical Immunology, vol. 120, no. 3, pp. 565-569, 2007.

[18] J. M. Spergel, "From atopic dermatitis to asthma: the atopic march," Annals of Allergy, Asthma and Immunology, vol. 105, no. 2, pp. 99-106, 2010.

[19] S. F. Thomsen, "Exploring the origins of asthma: lessons from twin studies," European Clinical Respiratory Journal, vol. 1, pp. $1-42,2014$.

[20] S. V. Glinianaia, J. Rankin, and M. Renwick, "Time trends in twin perinatal mortality in northern England, 1982-94," Twin Research, vol. 1, no. 4, pp. 189-195, 1998.

[21] T. Halvorsen, B. T. Skadberg, G. E. Eide, O. D. Røksund, K. H. Carlsen, and P. Bakke, "Pulmonary outcome in adolescents of extreme preterm birth: a regional cohort study," Acta Paediatrica, vol. 93, no. 10, pp. 1294-1300, 2004.

[22] T. M. McKeever, S. A. Lewis, C. Smith et al., "Siblings, multiple births, and the incidence of allergic disease: a birth cohort study using the West Midlands general practice research database," Thorax, vol. 56, no. 10, pp. 758-762, 2001.

[23] R. A. H. M. van den Oord and A. Sheikh, "Filaggrin gene defects and risk of developing allergic sensitisation and allergic disorders: systematic review and meta-analysis," British Medical Journal, vol. 339, Article ID b2433, 2009.

[24] S. F. Thomsen, C. S. Ulrik, K. O. Kyvik et al., "The incidence of asthma in young adults," Chest, vol. 127, no. 6, pp. 1928-1934, 2005.

[25] B. Wüthrich, "Clinical aspects, epidemiology, and prognosis of atopic dermatitis," Annals of Allergy, Asthma and Immunology, vol. 83, no. 5, pp. 464-470, 1999.

[26] S. J. Brown, A. Sandilands, Y. Zhao et al., "Prevalent and lowfrequency null mutations in the filaggrin gene are associated with early-onset and persistent atopic eczema," Journal of Investigative Dermatology, vol. 128, no. 6, pp. 1591-1594, 2008.

[27] J. N. W. N. Barker, C. N. A. Palmer, Y. Zhao et al., "Null mutations in the filaggrin gene ( $F L G)$ determine major susceptibility to early-onset atopic dermatitis that persists into adulthood," Journal of Investigative Dermatology, vol. 127, no. 3, pp. 564-567, 2007.

[28] H. Rupnik, M. Rijavec, and P. Korošec, "Filaggrin loss-offunction mutations are not associated with atopic dermatitis that develops in late childhood or adulthood," British Journal of Dermatology, vol. 172, no. 2, pp. 455-461, 2015.

[29] N. G. Heede, J. P. Thyssen, B. H. Thuesen, A. Linneberg, and J. D. Johansen, "Anatomical patterns of dermatitis in adult filaggrin mutation carriers," Journal of the American Academy of Dermatology, vol. 72, no. 3, pp. 440-448, 2015.

[30] T.-L. Hackett, H. G. De Bruin, F. Shaheen et al., "Caveolin1 controls airway epithelial barrier function implications for asthma," American Journal of Respiratory Cell and Molecular Biology, vol. 49, no. 4, pp. 662-671, 2013.

[31] E. L. Simpson, T. M. Berry, P. A. Brown, and J. M. Hanifin, "A pilot study of emollient therapy for the primary prevention of atopic dermatitis," Journal of the American Academy of Dermatology, vol. 63, no. 4, pp. 587-593, 2010.

[32] C. Hoare, A. Li Wan Po, and H. Williams, "Systematic review of treatments for atopic eczema," Health Technology Assessment, vol. 4, pp. 1-191, 2000. 
[33] K. Horimukai, K. Morita, M. Narita et al., "Application of moisturizer to neonates prevents development of atopic dermatitis," Journal of Allergy and Clinical Immunology, vol. 134, no. 4, pp. 824-830.e6, 2014.

[34] E. L. Simpson, J. R. Chalmers, J. M. Hanifin et al., "Emollient enhancement of the skin barrier from birth offers effective atopic dermatitis prevention," The Journal of Allergy and Clinical Immunology, vol. 134, no. 4, pp. 818-823, 2014.

[35] J. T. Bell and T. D. Spector, "A twin approach to unraveling epigenetics," Trends in Genetics, vol. 27, no. 3, pp. 116-125, 2011.

[36] J. T. Bell and R. Saffery, "The value of twins in epigenetic epidemiology," International Journal of Epidemiology, vol. 41, no. 1, pp. 140-150, 2012.

[37] A. Reyes, M. Haynes, N. Hanson et al., "Viruses in the faecal microbiota of monozygotic twins and their mothers," Nature, vol. 466, no. 7304, pp. 334-338, 2010.

[38] P. J. Turnbaugh, M. Hamady, T. Yatsunenko et al., "A core gut microbiome in obese and lean twins," Nature, vol. 457, no. 7228, pp. 480-484, 2009.

[39] J. Dicksved, J. Halfvarson, M. Rosenquist et al., "Molecular analysis of the gut microbiota of identical twins with Crohn's disease," ISME Journal, vol. 2, no. 7, pp. 716-727, 2008.

[40] W. Cozen, G. Yu, M. H. Gail et al., "Fecal microbiota diversity in survivors of adolescent/young adult Hodgkin lymphoma: a study of twins," British Journal of Cancer, vol.108, no. 5, pp. 1163$1167,2013$. 


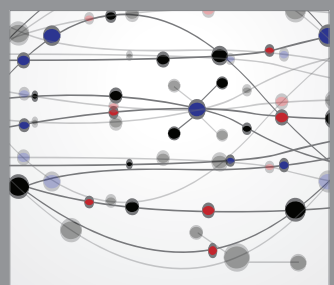

The Scientific World Journal
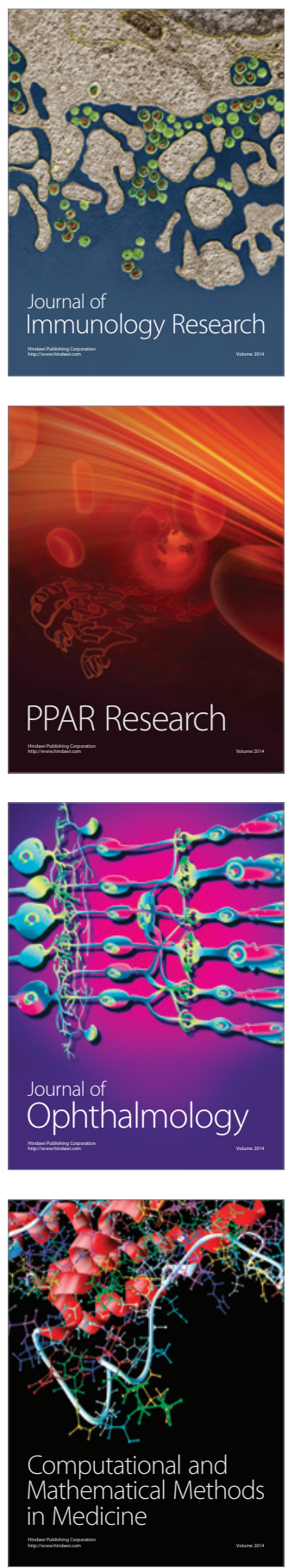

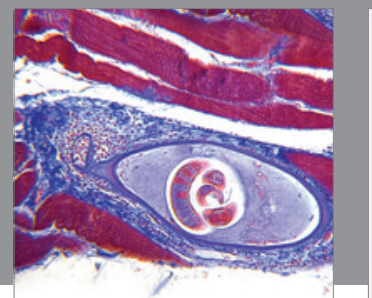

Gastroenterology

Research and Practice
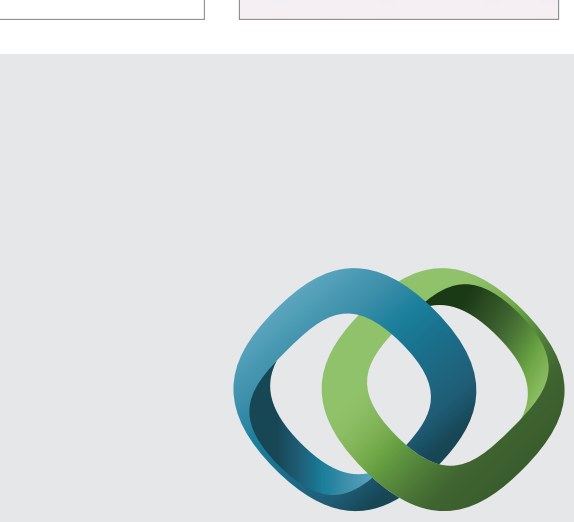

\section{Hindawi}

Submit your manuscripts at

http://www.hindawi.com
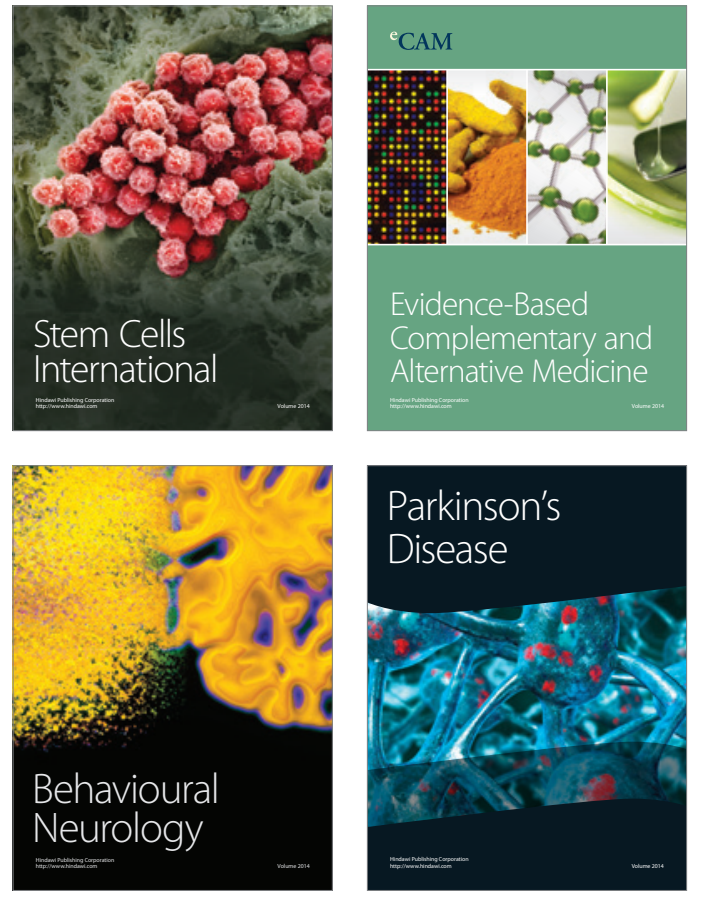
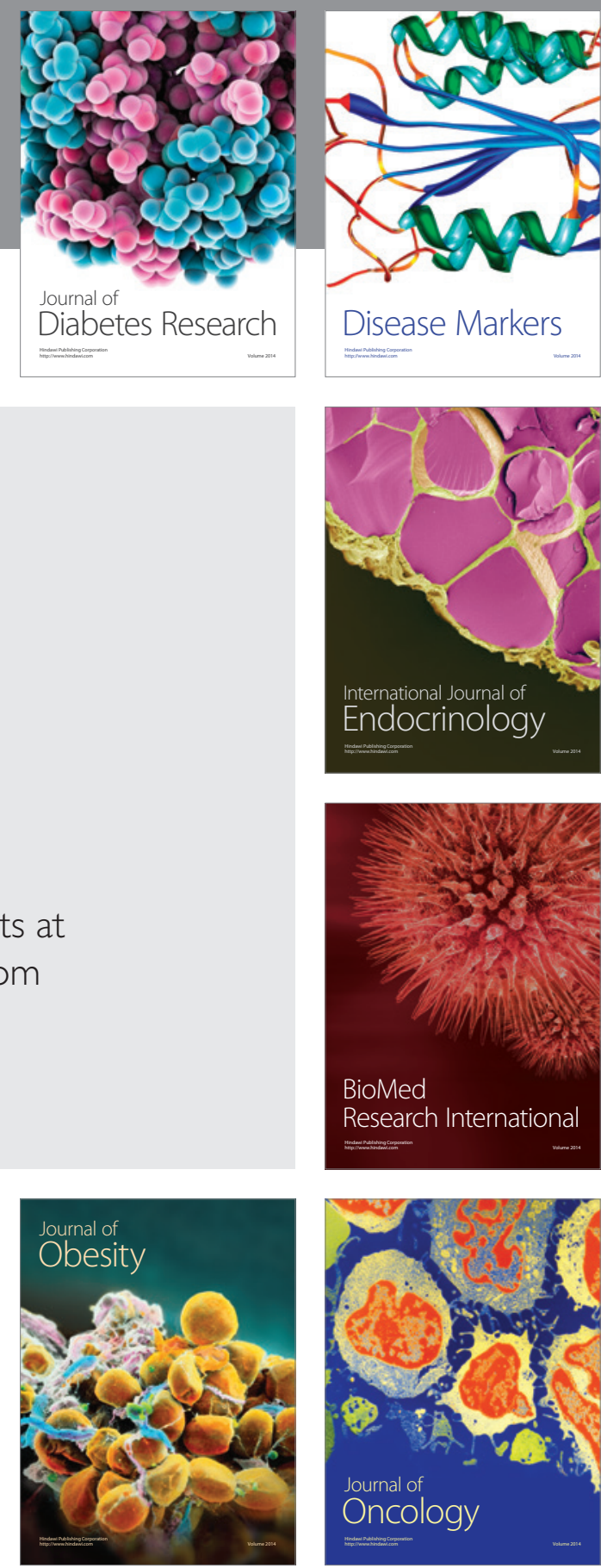

Disease Markers
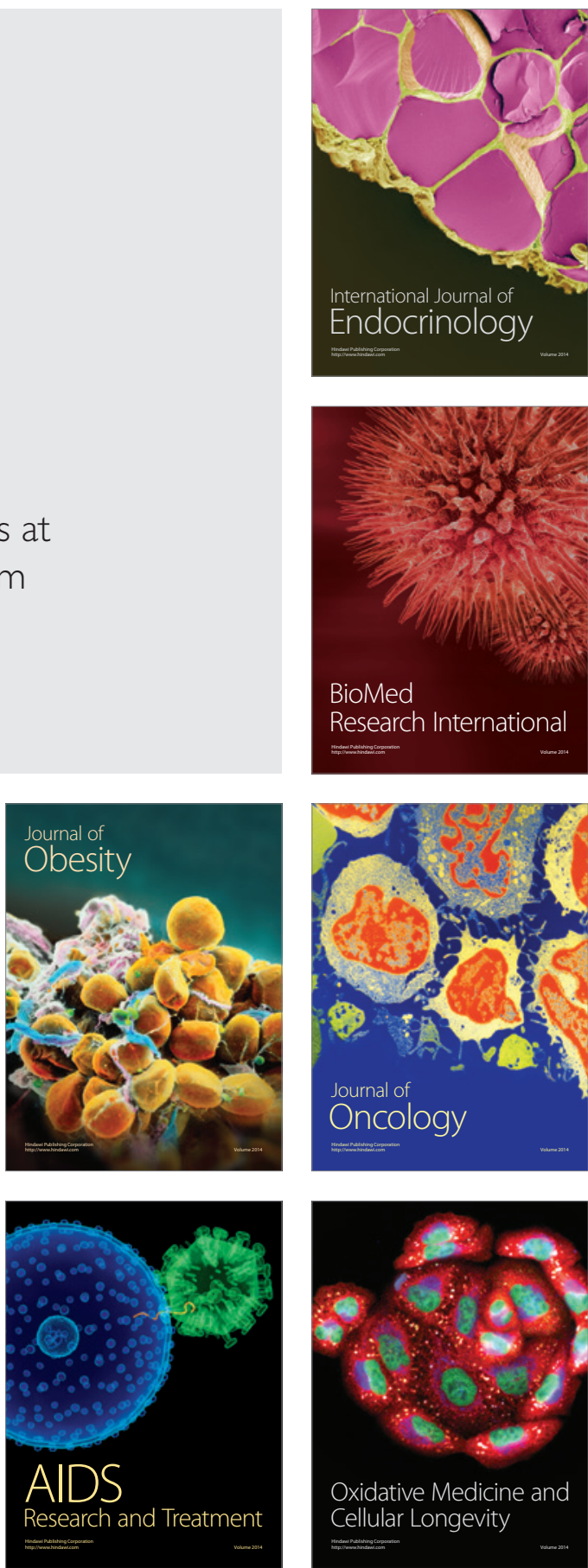